\title{
Microtubules and Actin Cytoskeleton of Cryptococcus neoformans as Targets for Anticancer Agents to Potentiate a Novel Approach for New Antifungals
}

\author{
Marie Kopecká \\ Department of Biology, Faculty of Medicine, Masaryk University, Brno, Czech Republic
}

\section{Key Words \\ Cryptococcus neoformans · Cytoskeleton - Microtubule inhibitors · Actin inhibitors · Microscopy}

\begin{abstract}
Background: We investigated the targeting of microtubules (MT) and F-actin cytoskeleton (AC) of the human pathogenic yeast Cryptococcus neoformans with agents for cancer therapy, in order to examine whether this yeast cytoskeleton could become a new antifungal target for the inhibition of cell division. Methods: Cells treated with 10 cytoskeleton inhibitors in yeast extract peptone dextrose medium were investigated by phase-contrast and fluorescence microscopy, and growth inhibition was estimated by cell counts using a Bürker chamber and measuring absorbance for 6 days. Results: Docetaxel, paclitaxel, vinblastine sulfate salt, cytochalasin D and chlorpropham [isopropyl $\mathrm{N}$-(3-chlorophenyl) carbamate] did not inhibit proliferation. The MT inhibitors methyl benzimidazole-2-ylcarbamate (BCM), nocodazole, thiabendazole (TBZ) and vincristine (VINC) disrupted MT and inhibited mitoses, but anucleated buds emerged on cells that increased in size, vacuolated and seemed to die after 2 days. The response of the cells to the presence of the actin inhibitor latrunculin $A(L A)$ includ-
\end{abstract}

ed the disappearance of actin patches, actin cables and actin rings; this arrested budding and cell division. However, in 3-4 days, resistant budding cells appeared in all 5 inhibitors. Disruption of the MT and AC and inhibition of cell division and budding persisted only when the MT and $A C$ inhibitors were combined, i.e. VINC + LA, BCM + LA or TBZ + LA. Conclusion: The MT and AC of C. neoformans are new antifungal targets for the persistent inhibition of cell division by combined F-actin and MT inhibitors.

(c) 2015 S. Karger AG, Basel

\section{Introduction}

Cryptococcus neoformans is a dangerous human pathogenic yeast that causes several serious diseases (e.g. cryptococcal pneumonia, cryptococcal meningitis and cutaneous cryptococcosis), not only in immune-deficient patients, but also in immune-competent people. Therapy is difficult, with frequent development of resistance and considerable mortality $[1,2]$.

This paper is dedicated to the memory of Miroslav Gabriel, MD, PhD and Associate Professor, with whom we initiated this research in 1999. He died on June 7, 2008.

\section{KARGER}

E-Mail karger@karger.com

www.karger.com/che
C 2015 S. Karger AG, Base

0009-3157/15/0613-0117\$39.50/0
Prof. MUDr. Marie Kopecká

Department of Biology, Faculty of Medicine

Masaryk University, Kamenice 5, A6

CZ-625 00 Brno (Czech Republic)

E-Mail mkopecka@med.muni.cz 
Fig. 1. a-p Phase-contrast micrographs of C. neoformans. a Control cells cultivated with $1 \%$ DMSO at the beginning of the experiment. Cells were treated for 2 days with $100 \mu \mathrm{M}$ of BCM (b), NOC (c) and VINC (d). e Control cells were cultivated with $2 \%$ DMSO for 2 days. Cells were treated for 2 days with $200 \mu \mathrm{M}$ of DOC (f), PAC (g), CD (h), LA (i) and $100 \mu \mathrm{M}$ of LA (j). Cells were treated with $100 \mu \mathrm{M}$ of LAT (k) and BCM (I) for 4 days. Cells were treated with combined $100 \mu \mathrm{M} \mathrm{LA}+100 \mu \mathrm{M}$ VINC for $4(\mathbf{m})$ and $6(\mathbf{n})$ days. Cells were treated with combined $100 \mu \mathrm{M} \mathrm{LA}+100 \mu \mathrm{M}$ BCM for 4 (o) and 6 (p) days. Scale bar: $10 \mu \mathrm{m}$.
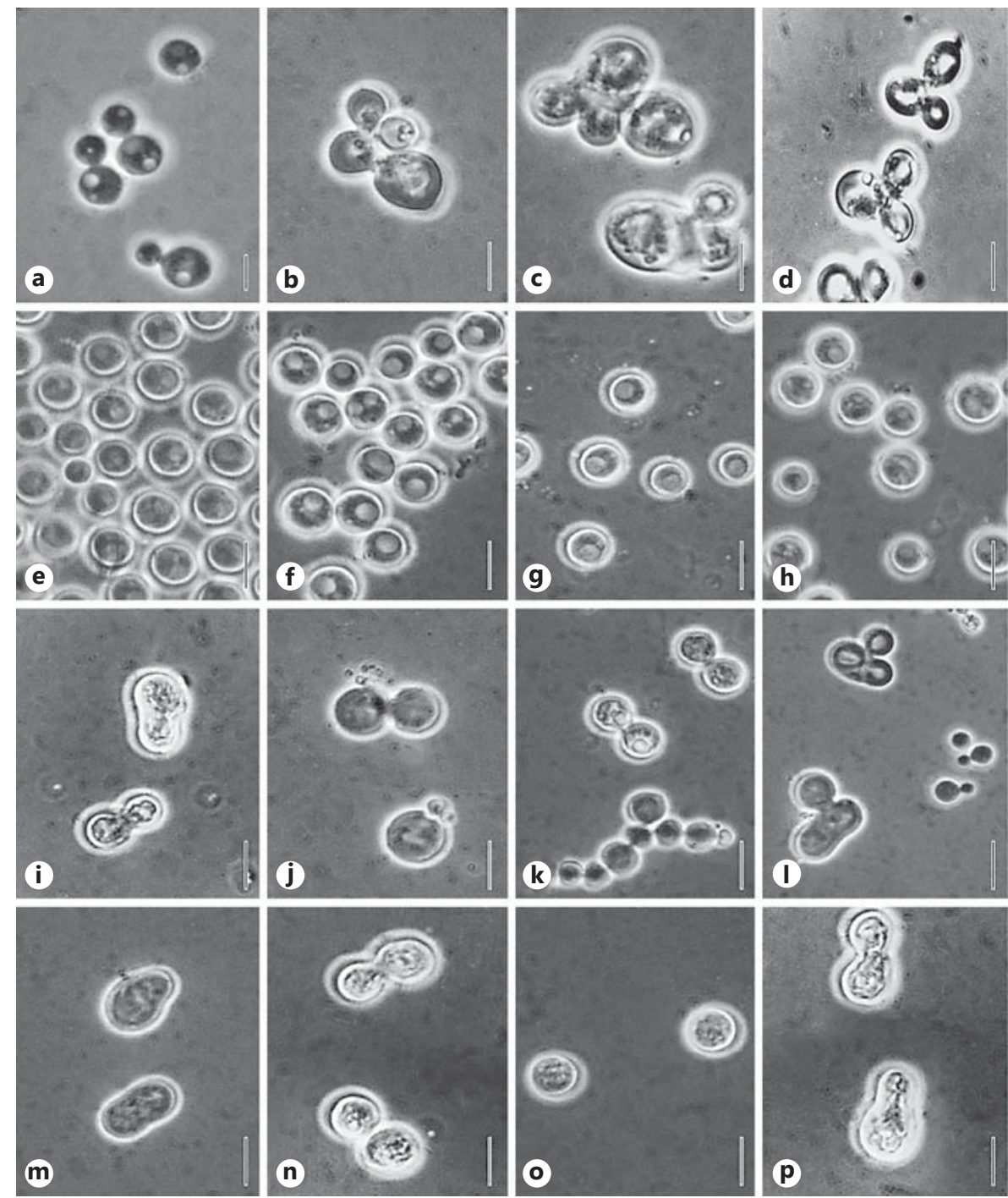

Our basic cell biological research of C. neoformans identified a cytoskeleton of microtubules (MT) and actin filaments (F-actin) involved in budding, mitosis and cytokinesis [3]. Here, several agents used in cancer therapy that inhibit MT or F-actin [4-8] were studied. Their effects on the F-actin cytoskeleton (AC) and the cell division of C. neoformans were investigated by fluorescence and phase-contrast microscopy in the search for new antifungal agents for the inhibition of cell division. Previously, C. neoformans was studied by electron microscopy [3], and the effects of some of these inhibitors were monitored $[9,10]$. Electron microscopy has also been used for examining inhibition in other yeasts [1115].

\section{Materials and Methods}

The yeast strain C. neoformans var. neoformans, IFM 41464 (CUH 34, 48-9943, 881, skin, serotype A), from the Medical Mycology Research Centre, Chiba University, Japan [16] was used. Media and cell cultivation were identical as described $[9,10]$.

\section{Inhibitor Treatments}

Methyl benzimidazole-2-ylcarbamate (BCM), vincristine (VINC) and latrunculin A (LA) were used as described $[9,10]$. Further inhibitors were nocodazole (NOC), thiabendazole (TBZ), docetaxel (DOC) and vinblastine sulfate salt (VINB) from Fluka, paclitaxel (PAC; BioChemica), and chlorpropham [isopropyl $\mathrm{N}$-(3-chlorophenyl) carbamate] (CIPC) and cytochalasin D (CD) from Sigma [11].

TBZ: $10 \mathrm{mM}$ stock solution was prepared by dissolving $2 \mathrm{mg}$ of the drug in $1.0 \mathrm{ml}$ of DMSO, and kept at $-20^{\circ} \mathrm{C}$. 
Table 1. Number of cells treated with $100 \mu \mathrm{M}$ of inhibitors and optical density of cells treated with $200 \mu \mathrm{M}$ of inhibitors

\begin{tabular}{lll}
\hline & $\mathrm{T}_{0}$ & At 6 days \\
\hline $\begin{array}{ll}\text { Number of cells }{ }^{\mathrm{a}} \\
\text { Control cells (1\% DMSO) }\end{array}$ & $5 \times 10^{5}$ & $1.5 \times 10^{8}$ \\
Control cells (2\% DMSO) & $5 \times 10^{5}$ & $1.5 \times 10^{8}$ \\
Cells treated with & & \\
BCM & $5 \times 10^{5}$ & $7.5 \times 10^{6}$ \\
NOC & $5 \times 10^{5}$ & $7.5 \times 10^{6}$ \\
TBZ & $5 \times 10^{5}$ & $7.5 \times 10^{6}$ \\
VINC & $5 \times 10^{5}$ & $4.5 \times 10^{7}$ \\
LA & $5 \times 10^{5}$ & $1.0 \times 10^{6}$ \\
VINC + LA & $5 \times 10^{5}$ & $7.5 \times 10^{5}$ \\
BCM + LA & $5 \times 10^{5}$ & $7.5 \times 10^{5}$ \\
\hline Optical density & & \\
Control cells (1\% DMSO) & 0.015 & 1.5 \\
Control cells (2\% DMSO) & 0.015 & 1.5 \\
Cells treated with & & \\
PAC & 0.015 & 1.7 \\
DOC & 0.015 & 1.7 \\
CIPC & 0.015 & 1.35 \\
CD & 0.015 & 1.5 \\
\hline
\end{tabular}

${ }^{\text {a }}$ Values represent number of cells per milliliter.

NOC: $10 \mathrm{mM}$ stock solution was prepared by dissolving $10 \mathrm{mg}$ of the drug in $3.0 \mathrm{ml}$ of DMSO, and kept at $-20^{\circ} \mathrm{C}$.

CIPC, PAC, DOC and VINB: $10 \mathrm{mM}$ stock solution was prepared by dissolving $5 \mathrm{mg}$ of the drug in $500 \mu \mathrm{l}$ of DMSO, and kept at $-20^{\circ} \mathrm{C}$.

$\mathrm{CD}$ : $10 \mathrm{~mm}$ stock solution was prepared by dissolving $5 \mathrm{mg}$ of the drug in $1 \mathrm{ml}$ of DMSO, and kept at $-20^{\circ} \mathrm{C}$.

Phase-contrast and fluorescence microscopy were performed as reported earlier [3]. Image Processing Software Adobe Photoshop CS5 and Adobe InDesign CS5 for Windows were used.

\section{Results}

\section{Phase-Contrast Microscopy}

Phase-contrast microscopy showed control budding cells (fig. 1a). The MT inhibitors BCM (fig. 1b), NOC (fig. 1c), VINC (fig. 1d) and TBZ in $100 \mu \mathrm{M}$ and $200 \mu \mathrm{M}$ concentrations did not inhibit bud growth but when bud and mother cells reached equal size, they failed to separate. Cells with several buds increased in size and vacuolated and seemed to die after 2 days. Control unbudding cells that reached the stationary phase of growth (fig. 1e) looked similar to the cells treated with DOC (fig. 1f), PAC (fig. 1g), VINB and CIPC which did not inhibit proliferation, similar to actin inhibitor CD (fig. 1h; table 1). Actin

Inhibitors of MT and F-actin in C. neoformans inhibitor LA [17] inhibited proliferation and cells lysed at areas of cell-wall growth (fig. 1i, j; table 1), as we have recently observed on electron microscopy $[9,10]$.

However, resistant budding cells appeared later in LA (fig. 1k), BCM (fig. 1l), NOC, TBZ and VINC. We attempted to prevent their occurrence by combining $100 \mu \mathrm{M} \mathrm{LA}+$ $100 \mu \mathrm{M}$ VINC, that was then added to the cells. This inhibited cell division (fig. $1 \mathrm{~m}, \mathrm{n}$ ), similar to using $100 \mu \mathrm{M} \mathrm{LA}+$ $100 \mu \mathrm{M}$ BCM (fig. 1o, p) and $100 \mu \mathrm{M} \mathrm{LA}+100 \mu \mathrm{M}$ TBZ.

\section{Fluorescence Microscopy}

Control cells (fig. 2a) stained with DAPI revealed nuclei (fig. 2b), those stained by rhodamine phalloidin revealed F-actin structures (fig. 2c) and those stained by antitubulin antibody revealed MT (fig. 2d) [3]. Cells inhibited by BCM (fig. 2e-h) and VINC (fig. 2i-l) revealed nuclei (fig. $2 \mathrm{f}, \mathrm{j}$ ) and evenly distributed actin patches (fig. 2g, k), but MT disappeared (fig. 2h, l), similar to when treated with NOC and TBZ. LA-inhibited cells (fig. $2 \mathrm{~m}-\mathrm{p}$ ) revealed nuclei (fig. $2 \mathrm{n}$ ) and a disappearance of F-actin structures (fig. 2o), but MT persisted (fig. 2p). Only when $100 \mu \mathrm{M}$ VINC $+100 \mu \mathrm{M}$ LA were combined and added to the cells (fig. $2 \mathrm{q}-\mathrm{t}$ ), was the nucleus revealed (fig. 2r), but the F-actin structures (fig. 2s) and MT (fig. 2t) disappeared, similar to after treatment with $100 \mu \mathrm{M} \mathrm{BCM}$ $+100 \mu \mathrm{M} \mathrm{LA}$ or $100 \mu \mathrm{M} \mathrm{TBZ}+100 \mu \mathrm{M} \mathrm{LA}$.

\section{Cell Proliferation}

The number of control cells at $\mathrm{T}_{0}$, i.e. $5 \times 10^{5} \mathrm{ml}^{-1}$, increased to $1.5 \times 10^{8} \mathrm{ml}^{-1}$ over 6 days; their optical density of 0.015 at $\mathrm{T}_{0}$ increased to 1.5 over 6 days, similar to cells treated with PAC, DOC, VINB, CD and CIPC that did not inhibit proliferation (table 1). The effect of VINC, BCM, NOC and TBZ increased the number of cells, i.e. $5 \times 10^{5} \mathrm{ml}^{-1}$ at $\mathrm{T}_{0}$ to $7.5 \times 10^{6}$ cells ml ${ }^{-1}$ over 6 days of inhibition, and in VINC, this number increased to $4.5 \times$ $10^{7} \mathrm{ml}^{-1}$. In LA, the number of cells at $\mathrm{T}_{0}$, i.e. $5 \times 10^{5} \mathrm{ml}^{-1}$, increased to $1.0 \times 10^{6}$ cells ml ${ }^{-1}$ after 6 days. In the combined $\mathrm{MT}+$ actin inhibitors, the number of cells at $\mathrm{T}_{0}$, i.e. $5 \times 10^{5}$ cells $\mathrm{ml}^{-1}$, increased in VINC + LA similar to that in LA alone, and was only $7.5 \times 10^{5} \mathrm{ml}^{-1}$ after 6 days similar to that in $\mathrm{BCM}+\mathrm{LA}$ and $\mathrm{TBZ}+\mathrm{LA}$, indicating the most efficient inhibition of proliferation.

\section{Discussion}

We investigated the targeting of the cytoskeleton filaments of C. neoformans with agents for cancer therapy, in order to potentiate a novel therapeutic antifungal ap- 
Fig. 2. a-t Fluorescent microscopy of $C$. neoformans. a-d Control cells without inhibitors. e-t Cells treated with inhibitors, fixed, stained with rhodamine phalloidin for actin, antitubulin antibody for MT and DAPI for nuclear staining. a Phase contrast (PC). b DAPI. c AC. d MT. e-h Cells treated with $100 \mu \mathrm{M}$ of BCM for $8 \mathrm{~h}$. e PC. f DAPI. $\mathbf{g}$ AC. $\mathbf{h}$ MT. i-I Cells treated with $100 \mu \mathrm{M}$ of VINC for $20 \mathrm{~h}$. i PC. j DAPI. k AC. I MT. m-p Cells treated with $100 \mu \mathrm{M}$ of LA for 4 h. $\mathbf{m}$ PC. $\mathbf{n}$ DAPI. o AC. $\mathbf{p}$ MT. $\mathbf{q}-\mathbf{t}$ Cells treated with a combination of 100 $\mu \mathrm{M} L A+100 \mu \mathrm{M}$ VINC for $4 \mathrm{~h}$. q PC. r DAPI. s AC. t MT. Scale bar: $10 \mu \mathrm{m}$.
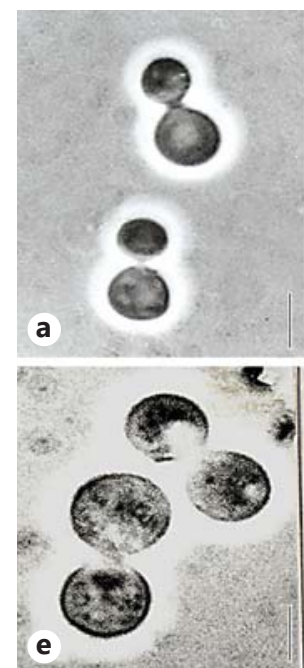

b
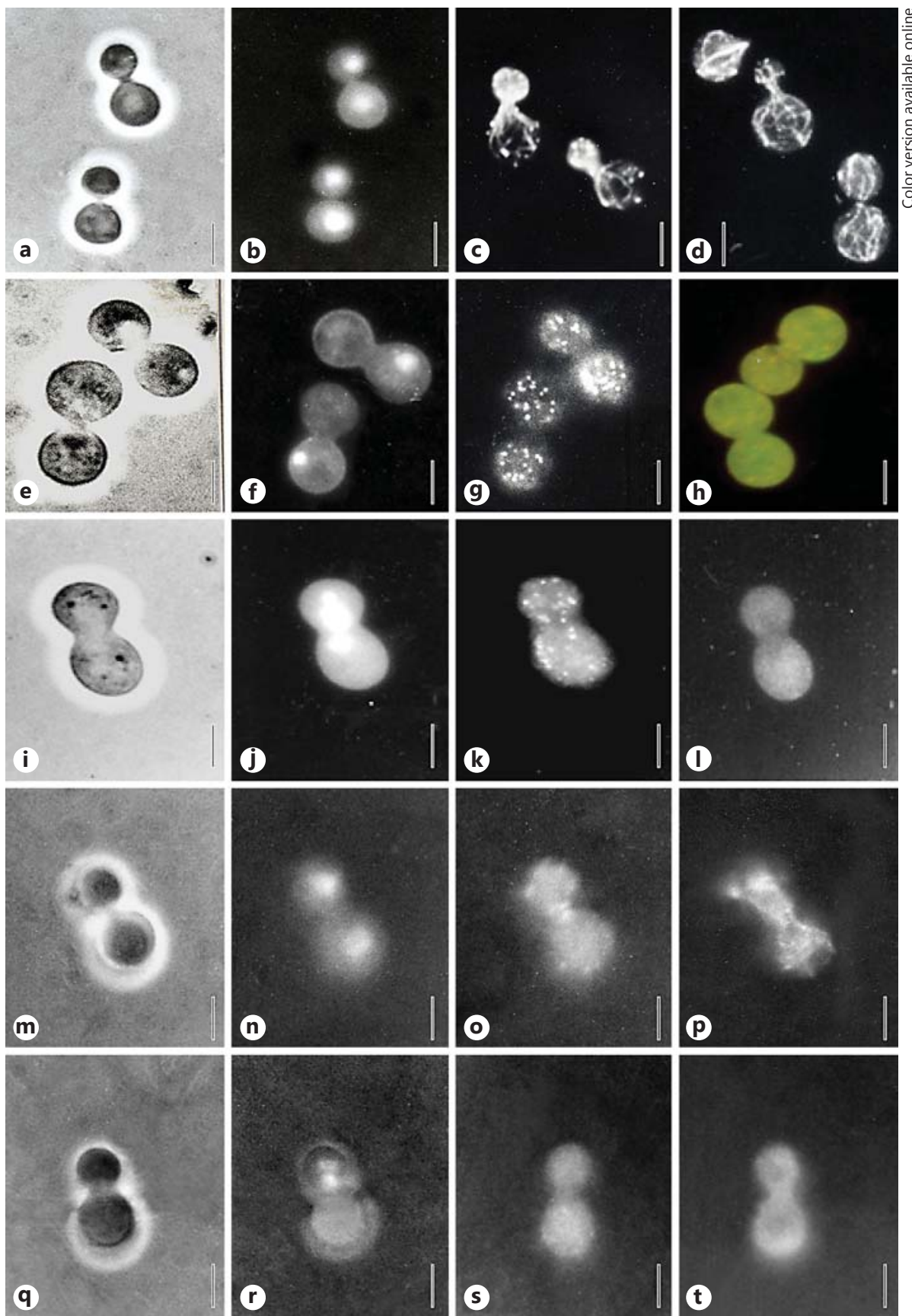

proach. The single MT inhibitors VINC, BCM, NOC and TBZ disrupted MT and blocked cells at the metaphase checkpoint $[4,18]$, monitoring joining of chromosomes to the mitotic spindle that cannot exit mitosis and realize cytokinesis. F-actin persisted, but resistant budding cells appeared later. The F-actin inhibitor LA disrupted F-actin and inhibited cytokinesis, but mitosis did not proceed either. Nakaseko and Yanagida [19] described the actin checkpoint monitoring F-actin during the M-phase that stops mitosis when F-actin is damaged; this is why mitosis did not proceed in LA-treated cells. Even though our results seemed promising during the first 3 days, resistant cells appeared here as well. We do not know whether cells metabolized the inhibitors, whether overproduction of efflux pumps removed the inhibitors, whether overexpression of alternative cytoskeleton proteins made cells resis- 
tant to the inhibitors or whether the $100 \mu \mathrm{M}$ inhibitor concentration containing $6.022 \times 10^{16}$ molecules did not inhibit all $5 \times 10^{5}$ cells ml $^{-1}$ (i.e. $6.022 \times 10^{16}: 500,000=1.20$ $\times 10^{11}$ inhibitor molecules per cell). Only when a $100 \mu \mathrm{M}$ concentration of an MT inhibitor was combined with a 100 $\mu \mathrm{M}$ concentration of an actin inhibitor, did $2.40 \times 10^{11}$ inhibitor molecules inhibit all $5 \times 10^{5}$ cells $\mathrm{ml}^{-1}$ and no resistant cells appeared. The inhibition was also effective with $\mathrm{CD}$ and BCM in the black fungus, Aureobasidium pullulans [13], but the combination of CD + BCM was found to be the most efficient (M.K. and Miroslav Gabriel, unpubl. data). LA + BCM combined also gave rise to the most efficient inhibition of the proliferation of the yeast, Fellomyces fuzhouensis $[14,15]$. It remains open to question whether combined MT + AC inhibitors can also inhibit other yeast pathogens, e.g. Candida albicans. VINC [20] and LA [21] alone were effective [20,21], so, in combination, they may also inhibit $C$. albicans as well as other fungi that contain MT and actin filaments. Another open question is whether such combined MT + actin inhibitors could prevent the occurrence of resistant cells in human cancers which contain the intermediate filaments absent in fungi.

\section{Conclusion}

DOC, PAC, VINB, CD and CIPC did not inhibit the proliferation of $C$. neoformans cells. BCM, NOC, TBZ and VINC disrupted MT, LA disrupted the AC and proliferation was temporarily inhibited, but resistant cells appeared in all 5 samples. Only when we combined VINC + LA, BCM + LA and TBZ + LA, were both the MT and $A C$ disrupted, and persistent inhibition of budding and nuclear and cell divisions persisted. These combined inhibitors should first be tested for local application on cutaneous cryptococcosis.

\section{Acknowledgement}

The authors thank Prof. A. Svoboda and Assoc. Prof. J. Tomandl for kind help and V. Ramíková and J. Šlancar for technical help. The research was supported by 3 grants from the Grant Agency of the Czech Republic: GAP 310/00/0391 and 310/06/0605 (M.K.) and GAP 310/03/1195 (Miroslav Gabriel). Institutional support from the Masaryk University, Brno, in 2009-2015 enabled continuation of this work.

\section{References}

1 Lui G, Lee N, Ip M, Choi KW, Tso YK, Lam E, Chau S, Lai R, Cockram CS: Cryptococcosis in apparently immune-competent patients. QJM 2006;99:143-151.

2 Sable CA, Strohmaier KM, Chodakewitz JA: Advances in antifungal therapy. Annu Rev Med 2008;59:361-379.

3 Kopecká M, Gabriel M, Takeo K, Yamaguchi M, Svoboda A, Ohkusu M, Hata K, Yoshida S: Microtubules and actin cytoskeleton in Cryptococcus neoformans compared with ascomycetous budding and fission yeasts. Eur J Cell Biol 2001;80:303-311.

4 Jordan MA, Wilson L: Microtubules and actin filaments: dynamic targets for cancer chemotherapy. Curr Opin Cell Biol 1998;10:123130.

5 Davidse LC: Benzimidazole fungicides: mechanism of action and biological impact. Annu Rev Phytopathol 1986;24:43-65.

6 Mukhtar E, Adhami VM, Mukhtar H: Targeting microtubules by natural agents for cancer therapy. Mol Cancer Ther 2014;13:275-284.

7 Senderowicz AMJ, Kaur G, Sainz E, Laing C, Wayne D et al: Jasplakinolide's inhibition of the growth of prostate carcinoma cells in vitro with disruption of the actin cytoskeleton. J Natl Cancer Inst 1995;87:46-51.

8 Trendowski M: Exploiting the cytoskeletal filaments of neoplastic cells to potentiate a novel therapeutic approach. Biochim Biophys Acta 2014;1846:599-616.
9 Kopecká M: Effects of microtubule and actin inhibitors on Cryptococcus neoformans examined by scanning and transmission electron microscopy. Chemotherapy 2014;60:99-106.

10 Kopecká M, Yamaguchi M, Kawamoto S: The effects of F-actin inhibitor latrunculin A on pathogenic yeast Cryptococcus neoformans. Chemotherapy 2014;60:185-190.

11 Gabriel M, Horký D, Svoboda A, Kopecká M: Cytochalasin D interferes with contractile actin ring and septum formation in Schizosaccharomyces japonicus var. versatilis. Microbiology 1998;144:2331-2344.

12 Kopecká M, Yamaguchi M, Kawamoto S: The effects of F-actin inhibitor, latrunculin $\mathrm{A}$ on budding yeast, Saccharomyces cerevisiae. Microbiology 2015, Epub ahead of print.

13 Kopecká M, Gabriel M, Takeo K, Yamaguchi M, Svoboda A, Hata K: Analysis of microtubules and F-actin structures in hyphae and conidia development of the opportunistic human pathogenic black yeast Aureobasidium pullulans. Microbiology 2003;149:865-876.

14 Kopecká M, Gabriel M: Microtubules and actin cytoskeleton of potentially pathogenic basidiomycetous yeast as targets for antifungals. Chemotherapy 2009;55:278-286.
15 Kopecká M, Ilkovics L, Ramíková V, Yamaguchi M: Effect of cytoskeleton inhibitors on conidiogenesis and capsule in the long neck yeast Fellomyces examined by scanning electron microscopy. Chemotherapy 2010;56: 197-202.

16 Nishimura K, Miyaji M, Takeo K, Mikami Y, Kamei K, Yokoyama K, Tanaka R: IFM list of pathogenic fungi and actinomycetes with photomicrographs, ed 2. Culture Collection of Research Centre for Pathogenic Fungi and Microbial Toxicoses, Chiba University, Seibunsha, 1998 .

17 Spector I, Shochet NR, Kashman Y, Groweiss A: Latrunculins: novel marine toxins that disrupt microfilament organization in cultured cells. Science 1983;219:493-495.

18 Nigg E: Mitotic kinases as regulators of cell division and its checkpoints. Nat Rev Mol Cell Biol 2001;2:21-32.

19 Nakaseko Y, Yanagida M: Cell biology: cytoskeleton in the cell cycle. Nature 2001;412: 291-292.

20 Routh MM, Raut JS, Karuppayil SM: Dual properties of anticancer agents: an exploratory study on the in vitro anti-Candida properties of thirty drugs. Chemotherapy 2011;57: 372-380.

21 Hazan I, Liu H: Hyphal tip-associated localization of Cdc- 42 is F-actin dependent in Candida albicans. Eukaryot Cell 2002;1:856861. 